\title{
ANÁLISIS DE LOS SITIOS WEBS DE LOS DESTINOS DE LA ESPAÑA VERDE Y SINOPSIS DE LA EVOLUCIÓN DE LA PROMOCIÓN ON-LINE
}

\author{
Laurentino Bello Acebrón \\ Montserrat Penelas Cortés Bellas \\ Universidade da Coruña \\ https://doi.org/10.17979/redma.2009.01.03.4690
}

\section{Resumen}

Para gestionar adecuadamente la Promoción de un Destino Turístico, cada vez es más indispensable reducir el riesgo en la toma de decisiones ya que se hacen más complejas e inciertas. Los procesos de planificación estratégica y el diseño de estrategias de marketing exigen analizar variables de diversa índole, situaciones y comportamientos, tanto de entorno general como específico, así como aspectos relacionados con el mix de marketing que permitan que un destino sea competitivo y la imagen del mismo sea coherente y atractiva. Por lo tanto, se necesita desarrollar metodologías de investigación de mercados que faciliten información objetiva y relevante de manera ágil y eficiente a los decisores e instituciones del Sector Turístico.

Este estudio aspira a ofrecer un conjunto de reflexiones que permitan avanzar en el estudio y la gestión de la comunicación on-line de los destinos turísticos de la España Verde, para que responsables y promotores reúnan un mayor conocimiento que redunde en una mejora del planteamiento de las características de sus sitios webs que se presentan como imprescindibles para el usuario potencial y que son susceptibles de perfeccionamiento y desarrollo. 
Aporta una metodología específica para la evaluación y análisis de la web de un destino turístico.

Palabras clave: Marketing on-line, webs, España Verde.

\begin{abstract}
:
AN ANALYSIS OF WEBSITES BELONGING TO GREEN SPAIN DESTINATIONS: RESULTS OF THE EVALUATION OF EXPLORATORY RESEARCH

In order to adequately manage the Promotion of a Tourist Destination, it is becoming increasingly more important to reduce risk when making decisions, given that these are more and more complicated and uncertain. The processes of strategic planning and the design of marketing strategies require the analysis of diverse types of variables, situations and behaviour, both in the general and in the specific context, as well as aspects related to the marketing mix which allow a destination to be seen as attractive and coherent. As such, standards or indicators of measurement have to be developed in order to facilitate the production of objective and relevant information easily and efficiently for the decision makers within the marketing organisations and the institutions in the Tourist Sector.
\end{abstract}

This study aims to offer a set of reflections which allow us to move forward in the study and management of online communication regarding the Green Spain tourist destinations, through which those responsible and promoters bring together a greater amount of knowledge which would result in an improvement in the approach towards the characteristics of their website, which are essential for potential users and which are open to improvement and development.

We offer a specific methodology for the evaluation and analysis of the website of a tourist destination.

Key words: Online marketing, websites, Green Spain. 


\section{Resumo}

ANÁLISE DAS PÁGINAS WEB DOS DESTINOS DE "ESPANHA VERDE" PANORÂMICA DA EVOLUÇÃO DA PROMOÇÃO ONLINE

Para gerir adequadamente a promoção de um destino turístico é indispensável reduzir o risco das decisões, já que estas são cada vez mais complexas e incertas. Os processos de planificação estratégica e do desenho de estratégias de marketing exigem uma análise de variáveis de diversos tipos, de situações e de comportamentos tanto de forma geral como especifica, assim como os aspectos relacionados com a mistura de marketing que permitam que o destino seja competitivo, coerente e atractivo. Portanto é necessário desenvolver metodologias de investigação de mercados que facilite a informação objectiva e relevante de forma fácil e eficiente a quem toma as decisões e para as instituições do sector turístico.

Este estudo visa oferecer um conjunto de reflexões que permitam avançar na analise e na gestão da comunicação online dos destinos turísticos da "Espanha Verde", para que os responsáveis e promotores reúnam um melhor conhecimento de forma a melhorar as suas páginas Web, que se apresentam imprescindíveis para o potencial usuário e são susceptíveis de desenvolvimento e aperfeiçoamento.

Transmite um método específico para a avaliação e analise da página Web de um destino turístico.

Palavras-chave: Online Marketing, Páginas Web, Espanha Verde. 


\section{Introducción}

Los destinos turísticos han encontrado en Internet el aliado ideal para romper fronteras con reducidos costes de promoción y distribución a través de la red.

Sabemos que las TICs aplicadas al turismo son un tema prioritario, puesto que el comercio on-line es utilizado cada vez más en el caso del sector turístico.

Los estudios que argumentan este hecho son prolíficos, e independientemente de la heterogeneidad y disparidad de los datos aportados, todos convergen en la idea de un futuro esperanzador para el binomio Internet y turismo, y por ende la promoción institucional de los destinos turísticos on-line.

Por ello, en relación a la comercialización on-line, es preciso reforzar la presencia de los destinos y productos turísticos españoles en este canal, internet, estableciendo un marco de colaboración que permita optimizar esfuerzos y un mayor impacto de las acciones.

Una nueva estructura del negocio en los mercados emisores impulsada por las TIC, Internet y un nuevo tipo de consumidor habituado a su utilización exigen un nuevo modelo de gestión de la promoción turística orientado al perfeccionamiento e innovación de sus estrategias adaptadas a este medio.

Huelga mencionar el amplio espectro de posibilidades de este medio, las oportunidades que brinda a las organizaciones de marketing de los destinos, puesto que casi todas las técnicas o herramientas de comunicación pueden implementarse a través de la web de los destinos turísticos. Dichas oportunidades deberían ser mejor aprovechadas tanto por destinos turísticos domésticos como por destinos internacionales ya que los recursos tecnológicos disponibles para la promoción en la Web son viables para todos los destinos independientemente de su tamaño 
Por lo que respecta al "Marketing on-line", se deben fijar objetivos por parte de las administraciones relacionados con:

- la mejora de la calidad informativa de los portales de turismo de los destinos.

- la mejora de la eficacia promocional de los portales.

- el desarrollo de una estrategia de marketing on-line basada en la segmentación de la demanda.

Las cantidades de dinero que se invierten en sitios webs como parte de los esfuerzos de promoción de los destinos turísticos son cada vez más relevantes, pues progresivamente este medio va cobrando mayor importancia y por tanto, esfuerzo inversor. Evaluar el regreso de la inversión tiene cada vez mayor interés. Se debe avanzar tanto en la evaluación, retorno de la inversión como en el seguimiento de las actuaciones propuestas en los planes de marketing de los destinos en relación a este medio.

Puesto que algunas preguntas clave son: ¿Cómo se están promocionando los destinos turísticos en la red? ¿Los responsables y/o promotores de los destinos poseen suficiente conocimiento a su alcance?

¿Existen unos estándares definidos y consensuados para medir la eficacia de la promoción de los destinos vía web? ¿Se tiene en estima y consideración determinados parámetros que desde el punto de vista de los usuarios cubren sus necesidades y éstas son satisfechas?

Creemos que además de la opinión de los expertos, la última palabra la tiene el consumidor/usuario potencial de estas webs. Sus prioridades, necesidades y expectativas deben ser valoradas para retroalimentar el proceso de mejora y excelencia de los sitios webs de los destinos turísticos.

Nuestra propuesta metodológica se basa en una encuesta de prueba, de carácter exploratorio, que intenta aportar información preliminar para posteriormente desarrollar un estudio en profundidad. 


\section{Factores clave para el análisis de sitios web de destinos turísticos.}

Múltiples han sido los intentos de establecer un método de evaluación de sitios webs, muchos de ellos con interesantes y recientes aportaciones a considerar.

Las medidas de evaluación de sitios web han sido analizadas de muchas maneras y en muy diversos contextos, si bien es cierto, que este análisis ha sido mayoritariamente liderado por los expertos, sin embargo, la opinión del usuario es un factor relevante para retroalimentar el proceso de toma de decisiones. En este sentido, la valoración de sitios web se halla en etapas embrionarias de desarrollo.

El marketing basado en la web efectivamente requiere mejorar el atractivo de los sitios webs como un medio de comunicación. Identificar, desarrollar, y analizar los factores que puede influenciar o facilitar lo que el consumidor necesita (no sólo deberían englobar la calidad técnica del medio sino aspectos también relacionados con las expectativas y satisfacción del cliente).

Según algunos investigadores (Young A., Park y Ulrike Gretzel, 2008), los factores comunes de éxito más usuales analizados tanto en las webs de turismo son: (1) la Calidad de Información; (2) la Facilidad de Uso; (3) Seguridad /privacidad; (4) La Apariencia Visual; (5) Personalización; (6) Sensibilidad; (7) Interactividad; (8) Confianza; Y, (9) Cumplimiento.

El resultado de la investigación de estos autores, se concreta al establecer los factores clave identificados para las webs del sector turístico considerados en estudios anteriores (véase cuadro 1). 


\section{Cuadro 1}

Descripción de factores cruciales unificados de evaluación

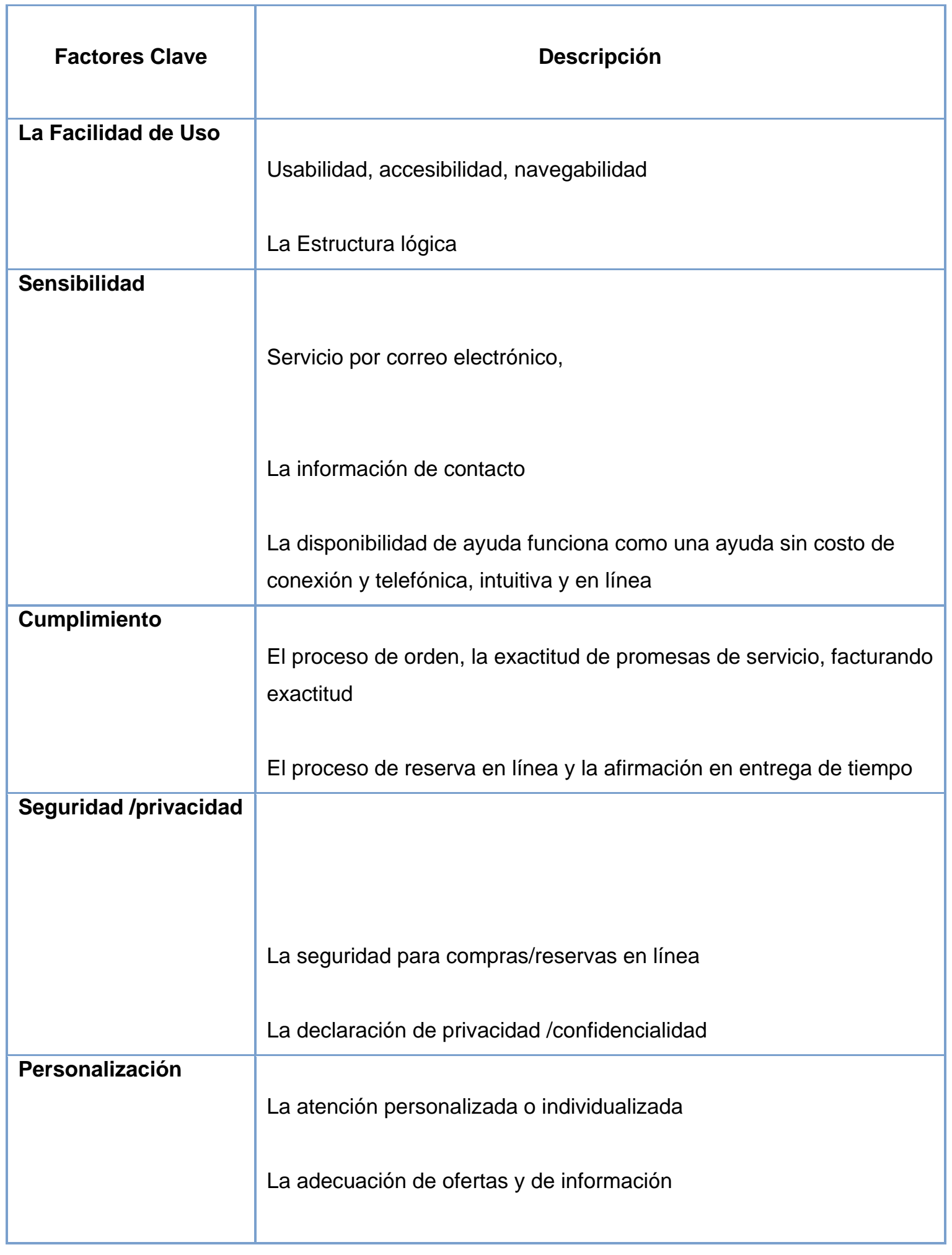




\begin{tabular}{|l|l|}
\hline La Apariencia Visual & $\begin{array}{l}\text { Atraer la atención } \\
\text { Estética de imagen }\end{array}$ \\
\hline $\begin{array}{l}\text { La Calidad de } \\
\text { Información }\end{array}$ & Variedad, alcance, moneda, concisión, exactitud de información \\
\hline Confianza & Credibilidad de Intenciones, de consistencia, de reconocimiento \\
\hline Interactividad & $\begin{array}{l}\text { Las características interactivas como las excursiones virtuales } \\
\text { La comunicación interactiva (FAQs, libros del invitado, charlas) }\end{array}$ \\
\hline
\end{tabular}

Fuente: Young A. Park and Ulrike Gretzel (2007).

El gran reto para la comunidad de investigación implica desarrollar las medidas que reflejan las nueve dimensiones anteriormente propuestas.

Estos factores facilitan una visión global de las dimensiones actualmente pertinentes $\mathrm{y}$ deben tomarse como un punto de partida para investigaciones futuras en vez de un criterio fijo, debido a las características evolutivas de este medio. También, para seleccionar los factores se debe pensar en las metas de marketing que una organización de marketing establece para su sitio Web. A muchas organizaciones de marketing les falta determinar objetivos evidentes para sus sitios Web así como también los planes estratégicos de desarrollo para sus marketing on-line. La evaluación del sitio Web es de uso reducido si sus resultados no son interpretados en el contexto de metas específicas.

Otros estudios analizados, nos aportan modelos de evaluación muy completos para evaluar las webs desde el punto de vista de las organizaciones de marketing de los destinos. En el caso del estudio de la OMT (2005), que presenta una definición de criterios de calidad y factores de éxito esenciales para sitios web de destinos muy exhaustiva, con el fin de garantizar que un sitio web no sólo satisfaga plenamente los deseos y las necesidades de los usuarios, sino también pueda garantizar que un sitio web contribuya plenamente a los objetivos de la organización.

Lo que es necesario evidenciar es que con la revolución actual que supone la introducción de la tecnología social o 2.0. La web convencional no es suficiente para promocionar un destino. 
De los estudios publicados más recientemente destacamos el de la O.M.T (2008), que analiza las posibilidades que brinda el e-marketing incorporando las tecnologías actuales 2.0 para la promoción de los destinos e introduce así nuevas fórmulas y/o desarrollos de e-marketing, que en estos momentos se encuentran en proceso de implantación. De hecho la Comunidad Valenciana, una de las comunidades analizadas en este estudio, ha creado su plan de marketing y reformado su web con un enfoque 2.0. Otras pioneras han sido Madrid o Andalucía que centra su atención en la gestión de las redes sociales. En la siguiente tabla se presenta un resumen de las técnicas que un DMO (Organización de marketing de destinos) puede implementar utilizando múltiples medios y especialmente la web, que se ha denominado 2.0, descrito adecuadamente por Celaya, J. (2008)

\section{Cuadro 2}

\section{Apreciación global de las técnicas del e-marketing diferentes en cada fase del "viaje del cliente"}

\begin{tabular}{|c|c|c|}
\hline Trayecto del consumidor & $\begin{array}{l}\text { Ciclo de comunicación } \\
\text { (Respuesta del DMO a las } \\
\text { necesidades del cliente) }\end{array}$ & $\begin{array}{l}\text { Actividades de E-marketing } \\
\text { encaminadas al cliente }\end{array}$ \\
\hline $\begin{array}{l}\text { Fase de expectativas y } \\
\text { selección }\end{array}$ & $\begin{array}{l}\text { Creando conocimiento, } \\
\text { compromiso, expectativas, } \\
\text { despertando el interés y } \\
\text { emoción, entusiasmándole } \\
\text { con ideas específicas }\end{array}$ & $\begin{array}{l}\text { *La proyección de la marca y } \\
\text { el contenido motivador, } \\
\text { incluyendo el video en la web } \\
\text { y la TV Interactiva. } \\
\text { * Promociones de Correo } \\
\text { electrónico / marketing viral } \\
\text { * La distribución de } \\
\text { información a través del } \\
\text { intermediarios de gran } \\
\text { influencia, como Expedia, } \\
\text { Travelocity, World Travel } \\
\text { Guide, Concierge and Rough } \\
\text { Guide. } \\
\text { * Optimización en motores de }\end{array}$ \\
\hline
\end{tabular}




\begin{tabular}{|c|c|c|}
\hline & & $\begin{array}{l}\text { búsqueda (SEO) / promoción } \\
\text { por valores/palabras clave, } \\
\text { experiencias y motivaciones } \\
\text { * CRM con medios de } \\
\text { comunicación y agencias de } \\
\text { viaje - para generar historias } \\
\text { e imágenes }\end{array}$ \\
\hline Planificación & $\begin{array}{l}\text { Proporcionando información } \\
\text { "concreta" }\end{array}$ & $\begin{array}{l}\text { * Por ejemplo, información } \\
\text { sobre el transporte, } \\
\text { alojamiento y eventos, etc. } \\
\text { * Herramientas de } \\
\text { planificación para el uso de } \\
\text { clientes en la web, incluyendo } \\
\text { el itinerario y planificación de } \\
\text { la ruta } \\
\text { * Gestión de redes sociales } \\
\text { habilitando el intercambio de } \\
\text { contenidos } \\
\text { *Ofertas especiales y } \\
\text { promociones vía email }\end{array}$ \\
\hline Reserva & $\begin{array}{l}\text { Facilitando y permitiendo } \\
\text { reservas }\end{array}$ & $\begin{array}{l}\text { * Facilidad de búsqueda de } \\
\text { producto en la web } \\
\text { * Proporcionando reservas en } \\
\text { el sitio web del destino o } \\
\text { facilitar la reserva a través de } \\
\text { terceras partes incluyendo } \\
\text { motores de búsqueda de } \\
\text { comparación de precio y } \\
\text { facilitando la disponibilidad. }\end{array}$ \\
\hline Visita & $\begin{array}{l}\text { Servicios para los visitantes } \\
\text { en destino }\end{array}$ & $\begin{array}{l}\text { *Planificación de itinerarios } \\
\text { interactivos para visitantes. } \\
\text { * Uso de nuevos medios de } \\
\text { comunicación para contar } \\
\text { historias in situ-interpretación } \\
\text { y recreación. } \\
\text { *Comunicar ofertas oportunas } \\
\text { a móviles con un SMS corto o } \\
\text { vía e-mail. }\end{array}$ \\
\hline
\end{tabular}




\begin{tabular}{|c|c|c|}
\hline & & $\begin{array}{l}\text { * Información y herramientas } \\
\text { para el uso por centros del } \\
\text { información y otros } \\
\text { * Distribución a los hoteles, } \\
\text { casas rurales y otras áreas } \\
\text { de recepción de visitantes, } \\
\text { vía TV y quioscos. }\end{array}$ \\
\hline $\begin{array}{l}\text { Post-visita (Recuerdo y } \\
\text { recomendación) }\end{array}$ & $\begin{array}{l}\text { Mantenimiento de la relación } \\
\text { a través de la investigación y } \\
\text { seguimiento de la acción }\end{array}$ & 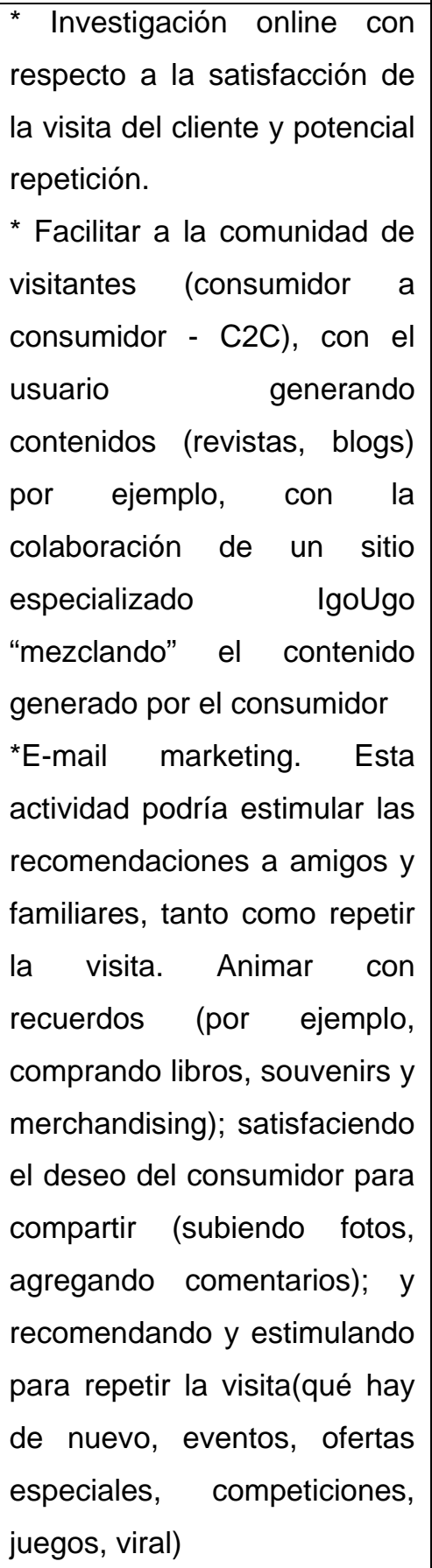 \\
\hline
\end{tabular}

Fuente: OMT ( 2008) 
De todas estas técnicas, digamos que la más elemental es lograr un posicionamiento adecuado en buscadores, sea de forma natural (SEO) o bien por medio de pago (SEM).

Algunos de estos aspectos se han incorporado en nuestra encuesta a usuarios, destacando de los resultados el bajo nivel de valoración que en la fecha tenían las webs 2.0 (simplificando la significación en sentido amplio de la 2.0 a foros, chats, contenido de vídeos en las webs, etc. como pilar para compartir experiencias y emociones), y la baja importancia que le otorgaban los usuarios a este concepto.

Ahora bien, como bien dice William Bakker (director de eBusiness de Tourism British Columbia), "no por integrar blogs, comunidades, fuentes externas de contenido,... el destino ya es 2.0 (sería mejor hablar de 1.5)". Hace falta que el gestor de dicha web participe de la conversación entre la demanda y la oferta.

En este sentido, otros estudios expuestos y presentados en TURITEC 2008, reflejan los resultados sobre el uso de determinadas herramientas de tecnología social (véase siguiente cuadro), que no trasmiten en la actualidad ni mucho menos la apuesta activa entre los jóvenes de la Comunidad de Madrid por las tecnologías sociales.

Son los sitios web de comparación de precios los más utilizados, así como los mapas interactivos, siendo lo menos utilizados los podcast. En el caso de la participación activa, las herramientas en las que más se "cuelga información" son las páginas web de fotos. Estos resultados obedecen a la facilidad de acceso a la información sobre críticas y mapas interactivos, que se encuentran a un click de distancia, además de encontrarse la información más centralizada y en menor número de sitios web, que en el caso de blogs y de comunidades de viajeros. 


\section{Cuadro 3}

\section{Uso de herramientas de tecnología social}

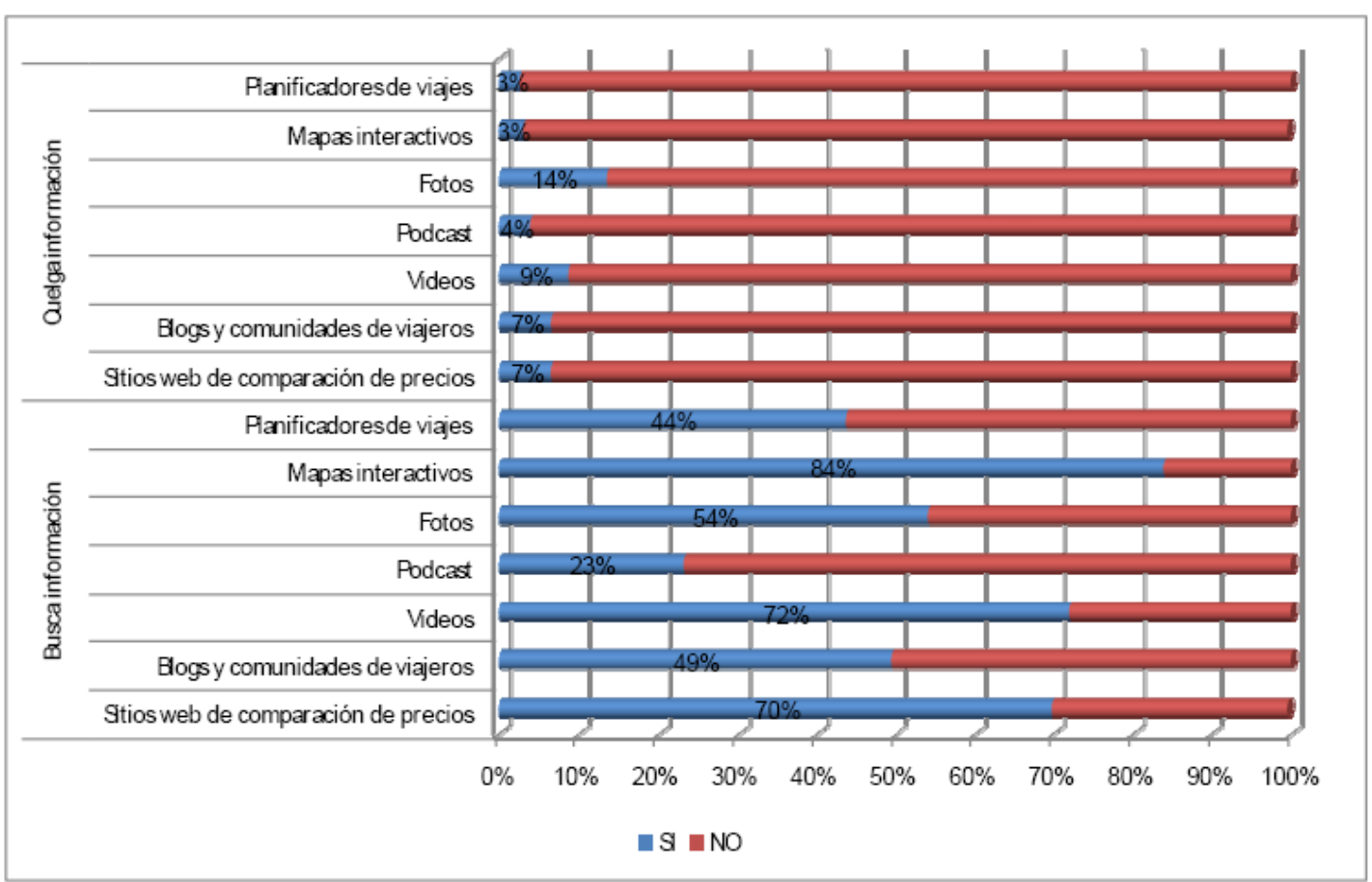

Fuente: TURITEC (2008)

Por lo tanto, la web está reestructurándose en estos momentos para evolucionar e incorporar esa interactividad, diálogo, opinión, prescripción etc. Sin duda el usuario será el protagonista, sin embargo el uso indiscriminado de algunas de estas tecnologías por parte de muchos usuarios y su conocimiento y aplicación por parte de los destinos turísticos está en proceso, si bien evoluciona vertiginosamente.

Lo que verdaderamente importa son las posibilidades de comunicación facilitadas por la web: usabilidad, interactividad, creación de opiniones, experiencias de otros viajeros, etc. El proceso hacia la implantación plena se podrá corroborar mediante el análisis comparativo entre el análisis que se establece en este documento y uno a posteriori, puesto que algunas Comunidades Autónomas, como por ejemplo la Comunidad Valenciana ya tienen Plan de Marketing 2.0. 
Análisis efectuados muy recientemente nos muestran esta participación o visibilidad a implantar por los destinos turísticos en la web 2.0. Celaya, J. (2009) evalúa la visibilidad de 26 ciudades o destinos en la web 2.0. Celaya plantea las siguientes herramientas para lograr visibilidad de las ciudades 0 destinos turísticos en la web y para valorar su presencia.

\section{Figura 1}

\section{Herramientas que otorgan visibilidad en la web}

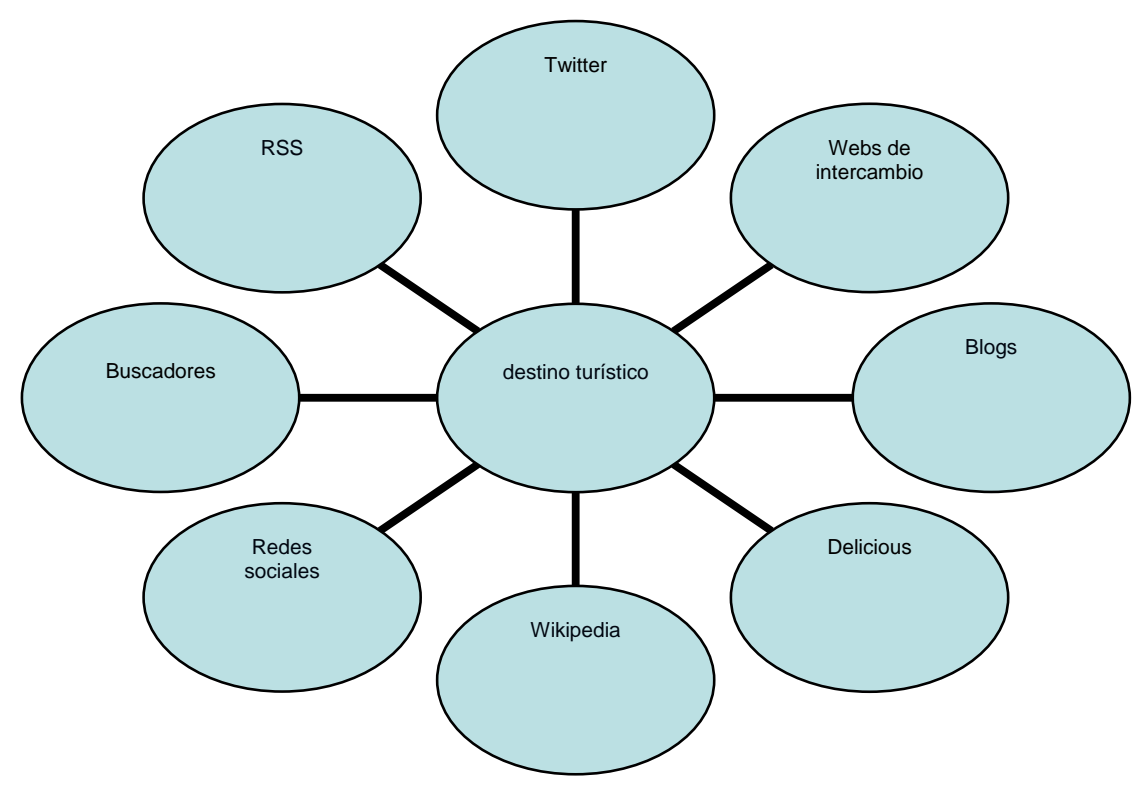

Fuente: Celaya, J. (2008)

Los resultados arrojan resultados todavía no muy optimistas en ciertos aspectos: en cuanto a la valoración, muchas cuentan con sala de prensa virtual un 38\% de las ciudades analizadas, mientras sólo un 15\% ofrece RSS. Sin embargo un $46 \%$ de las ciudades son accesibles (aspecto que bajo nuestro punto de vista es esencial). Poseen una alta presencia en wikipedia, no obstante, en cuanto a otras herramientas, no resultan tan visibles como cabría suponer, pues sólo un 8\% permite conversaciones con los ciudadanos, tan sólo 
un $4 \%$ permite publicar vídeos de la ciudad vista por los ciudadanos o turistas, sólo un 4\% utiliza por el podcast.

Sobre la visibilidad se percibe una creciente presencia en Facebook y MySpace, en YouTube: 174 menciones sobre turismo por ciudad, 126 menciones por ciudad en redes especializadas como Culturizame.net, y escaso uso de Twitter.

Lo cierto es que independientemente de la planificación del e- marketing que los destinos se plantean en estos momentos, algunas de las necesidades esenciales para el turista vía web oficial del destino, a veces no se encuentran cubiertas. Es por eso que los usuarios tienen una perspectiva única y es necesario establecerla como el punto de partida para progresar tanto en aspectos de diseño y valoración de las webs antes de posicionarse, o bien, lograr una visibilidad en la web 2.0.

Algunos de estos criterios 2.0, los que hemos considerado más esenciales, se han incorporado a nuestro estudio exploratorio sobre webs de destinos, sin pretender ser exhaustivos, pues la encuesta elaborada en esta investigación se ha desarrollado on-line y con un margen de tiempo realmente reducido, por lo que se prioriza la brevedad frente a la extensión.-. Por lo tanto, se han seleccionado aquellos ítems más pertinentes o relevantes en cada apartado, y se han incluido otros referentes a la percepción de la imagen de la web por parte del usuario, innovación, etc., después de las entrevistas en profundidad realizadas a expertos.

En otros estudios de actualidad, son considerados otros parámetros para valorar las páginas oficiales de los destinos turísticos. Fernández et al (2006), realizan una investigación cuyo objetivo principal es analizar el grado de desarrollo de los sitios web de ciudades turísticas, especialmente en lo relacionado con dos aspectos clave: la usabilidad y la interactividad.

Los resultados de este estudio apuntan que las páginas analizadas poseen una mejor estructura, diseño y usabilidad, que interactividad. Por tanto, una de las 
conclusiones es que existe todavía para las webs oficiales de los destinos un potencial de recursos interactivos infrautilizado.

Los resultados de la investigación empírica de estos autores determinan que la mayoría de webs analizadas poseen una buena estructura. Por tanto, la cuestión de la usabilidad está bien tratada en la construcción de las páginas de destinos turísticos, aunque no tienen tan en cuenta el importante aspecto de los idiomas y las versiones culturales adaptadas disponibles. Siendo fundamental en turismo la adaptación cultural a los distintos mercados emisores, algunas webs todavía adolecen de este enfoque. Las webs utilizan poco la oportunidad de los registros para la previa utilización de los recursos interactivos. Con lo cual, la información que se obtiene por parte de los usuarios de la web es mínima. Como se ha afirmado anteriormente, se desaprovecha la posibilidad de obtener más información para realizar un marketing directo one to one que sugiera ofertas especializadas a medida de las necesidades de los consumidores. Luego concluimos que todavía existe un potencial para enfatizar algunos aspectos no contemplados en las webs de destinos.

Por último, si reflexionamos sobre el avance de comunicación de marca entre otros productos de consumo y destinos turísticos, hay varios aspectos en los que el producto genérico de consumo gana terreno con respecto a los destinos turísticos, como se manifiesta en el análisis comparativo que se presenta en el citado estudio de Fernández et al (2008).

Otro de los estudios que se consideran para la posterior determinación de nuestro propio análisis es el realizado por (Da Cruz, 2008). 
3. Objetivos y metodología para el análisis de las webs de destinos turísticos.

Con la finalidad de estudiar la importancia de las diferentes características que puede tener una Web, así como la valoración que otorgan los diferentes usuarios a diferentes páginas Webs alternativas y competidoras entre sí, se propone una metodología de una investigación descriptiva y se diseñó una investigación exploratoria cuyos resultados analizaremos en los siguientes apartados.

\subsection{Objetivos de la Investigación.}

El principal objetivo del estudio es analizar desde la perspectiva de los usuarios actuales y potenciales como valoran las diferentes Webs y la importancia que otorgan a cada una de las características posibles.

Este objetivo genérico, se plasma en la concreción de tres objetivos, que se detallan a continuación:

A) Análisis comparativo de las valoraciones que se puedan obtener de las diferentes Webs.

B) Jerarquizar las características según la importancia que le asignan los usuarios.

C) Obtener una valoración global de las diferentes Webs analizadas.

\subsection{Metodología de la Investigación.}

La metodología considerada para cumplir los objetivos fijados se estructura como se describe a continuación (véase cuadro 4)

A partir de una investigación preliminar en la que se recopiló información secundaria que permitió desarrollar las líneas básicas planteadas en el proyecto, se diseña el cuestionario, configurado a partir de una investigación cualitativa (Entrevistas en profundidad a siete expertos en páginas webs) y definitivamente aceptado después de realizar un pre-test.

REDMARKA UIMA-Universidad de A Coruña - CIECID

Año 1, Número 3, (2009), pp. 41-78 
No obstante por razones derivadas de recursos disponibles y de tiempo, se efectuó una encuesta "de prueba" con 44 encuestas válidas y de carácter exploratorio, que aunque sus resultados no se puedan inferir en términos estadísticos, sí son indicativos de ciertas tendencias y resulta de gran eficacia para verificar la metodología propuesta.

Se han aplicado técnicas estadísticas univariantes y bivariantes que han permitido conocer tanto las valoraciones de cada web como la importancia de cada una de las características.

Posteriormente, al tratamiento de los 21 ítems utilizados en la valoración de cada web, medido con una escala equivalente a la de Likert le aplicamos un Análisis Factorial de Componentes Principales, para así simplificar el conjunto de datos y reducir el número de variables. De la misma manera con el Análisis Factorial tratamos de identificar estructuras latentes "Factores" (Trespalacios, Vázquez y Bello,2005).

Este análisis nos permite condensar o resumir la información contenida en nuestro grupo de ítems o variables a un número menor, que nos permitirá crear nuevas variables que serán denominadas factores o componentes. Finalmente nos permite reunir a las variables en base a la existencia de una estructura común subyacente o interrelación fuerte entre todas ellas, para finalmente denominarlas en base a la interrelación encontrada.

Así se ha evaluado que nuestra matriz de datos contiene suficientes correlaciones para justificar la aplicación del análisis factorial.

Hemos obtenido una solución a priori de seis componentes observando que es una solución factorial que se ajusta muy bien al criterio de parsimonia, ya que seis componentes explican casi un $80 \%$ de porcentaje de varianza acumulada en comparativa con 21 factores que explicarían el 100\%.

En definitiva, el número tan reducido de datos disponibles por razones presupuestarias han limitado nuestra intención de realización de un análisis más completo y cuantitativo, de forma que no nos permite sacar conclusiones 
definitivas, sino simplemente mostrar cómo se puede aplicar la metodología propuesta, y cómo podríamos descubrir variables latentes (factores), que contribuiría a gestionar mejor nuestras webs.

En el cuadro siguiente se describe la ficha técnica de la encuesta propuesta y la de prueba realizada. 


\section{Cuadro 4}

\section{Ficha técnica}

\begin{tabular}{|c|c|c|}
\hline \multicolumn{3}{|c|}{ Procedimiento Metodológico } \\
\hline \multicolumn{2}{|c|}{ Investigación propuesta (Encuesta propuesta) } & \multirow{2}{*}{\begin{tabular}{|c|}
$\begin{array}{c}\text { Investigación exploratoria } \\
\text { (Encuesta de prueba) }\end{array}$ \\
Galicia
\end{tabular}} \\
\hline $\begin{array}{l}\text { Ámbito } \\
\text { geográfico }\end{array}$ & España & \\
\hline $\begin{array}{l}\text { Tamaño } \\
\text { Muestral }\end{array}$ & Cuestionarios válidos: 800 & Cuestionarios válidos: 44 \\
\hline $\begin{array}{l}\text { Tipo de } \\
\text { encuesta }\end{array}$ & $\begin{array}{l}\text { Personales a través de correo } \\
\text { electrónico con cuestionarios } \\
\text { estructurados }\end{array}$ & $\begin{array}{l}\text { Personales a través de correo } \\
\text { electrónico con cuestionarios } \\
\text { estructurados }\end{array}$ \\
\hline $\begin{array}{l}\text { Proceso de } \\
\text { Muestreo }\end{array}$ & $\begin{array}{l}\text { Muestreo polietapico estratificado } \\
\text { con afijación proporcional por } \\
\text { comunidades autonomas,edad y } \\
\text { sexo }\end{array}$ & Por conveniencia \\
\hline $\begin{array}{l}\text { Error } \\
\text { muestral }\end{array}$ & $\begin{array}{l}\text { Para } p=q=0,05 \text { y un nivel de } \\
\text { confianza de } 95 \%\end{array}$ & $\begin{array}{l}\text { Para } p=q=0,05 \text { y un nivel de } \\
\text { confianza de } 95 \%\end{array}$ \\
\hline $\begin{array}{l}\text { Trabajo de } \\
\text { Campo }\end{array}$ & Octubre INoviembre de 2008 & Junio/Julio 2008 \\
\hline \multirow[t]{3}{*}{$\begin{array}{l}\text { Análisis } \\
\text { estadístico: }\end{array}$} & $\begin{array}{l}\text { Análisis Univariante (Medias y } \\
\text { frecuencias). }\end{array}$ & $\begin{array}{l}\text { Análisis Univariante (Medias y } \\
\text { frecuencias). }\end{array}$ \\
\hline & 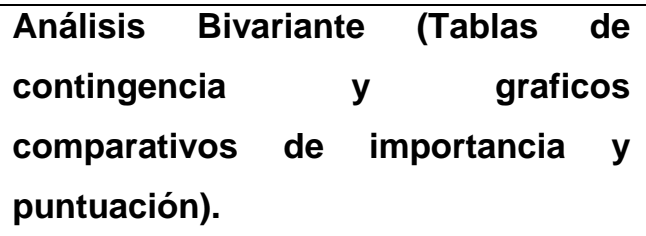 & $\begin{array}{l}\text { Análisis Bivariante } \\
\text { contingencia (Tablas de } \\
\text { comparativos de importancia y } \\
\text { puntuación). }\end{array}$ \\
\hline & $\begin{array}{llr}\text { Análisis } & \text { Multivariante } & \text { (Análisis } \\
\text { Factorial de componentes } \\
\text { principales) }\end{array}$ & $\begin{array}{l}\text { Análisis Multivariante (Análisis } \\
\text { Factorial de componentes } \\
\text { principales) }\end{array}$ \\
\hline $\begin{array}{l}\text { Programa } \\
\text { informático }\end{array}$ & SPSS 11.0 y SPAD 4.5 & SPSS 11.0 \\
\hline
\end{tabular}

Fuente: Elaboración propia. 


\section{Resultados e implicaciones.}

\subsection{Resultados de la investigación exploratoria.}

Con el presente informe se ofrece información visual en forma de gráficos sobre los resultados más relevantes, así como las principales conclusiones alcanzadas que resaltan los logros obtenidos durante el proceso investigador a la luz de los objetivos inicialmente planteados.

\subsubsection{Análisis descriptivo}

Con respecto al uso de las páginas webs de destinos turísticos se plantea si para estos destinos el uso de la página web se orientaba fundamentalmente a la contratación de servicios o bien mayoritariamente a la búsqueda de información. Las opciones propuestas eran si mayoritariamente accedían a éstas sólo para informarse, para informarse y comparar alternativas, para informarse y planificar su viaje o bien para contratar viajes y servicios turísticos.

Las conclusiones que se obtienen de este análisis es que la mayoría de los encuestados afirman que utilizan este medio no solamente para informarse, sino también para organizar o planificar su viaje, en concreto parece que un $50 \%$ de los usuarios de las webs organizan o planifican sus vacaciones a través de la misma, además de informarse del destino turístico, sin embargo muy pocos acceden a la web para contratar, en concreto un 9,1\% afirman contratar algún servicio o el viaje mediante Internet.

Un alto porcentaje de usuarios accede a la web para buscar sólo información, en concreto un $27,3 \%$ y un reducido número $11,4 \%$ compara además información en la web. 


\section{Gráfico 1}

\section{Motivo de acceso a webs de viajes}

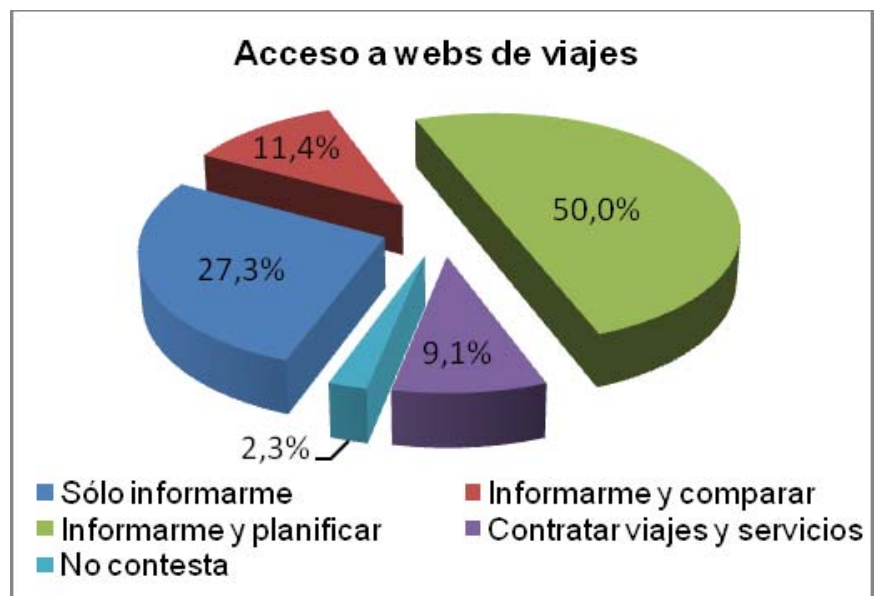

Fuente: Elaboración propia.

Estos datos se nos antojan muy significativos, ya que nos indican que más de la mitad de los encuestados que consultan webs de viajes, lo hacen con intención de informarse y un 50\% planifican su viaje.

A continuación, se clasifica a los encuestados con respecto al conocimiento o no que tuvieran previamente de las webs de destinos que se propone valorar.

Este aspecto puede influir o condicionar en cierta medida la percepción de la web por el usuario y por ende modificar sus respuestas. Desde este punto de vista, aquellos usuarios que ya hubieran navegado en las webs con antelación, estarían lógicamente más familiarizados con las mismas, hasta el punto de que parece lógico que la navegación les resulte más sencilla, el nivel de usabilidad sea también más sencillo o que encuentren mayor afinidad con estas webs previamente visitadas que con las que no están habitualmente acostumbrados a manejar.

De hecho, la web más visitada por los usuarios era la de Galicia (una mayoría abrumadora, un $81,8 \%$ ), como se puede observar en el siguiente gráfico. Esto 
es debido a que la base de datos del público que se utilizó para enviar las encuestas por correo electrónico, es decir, nuestro público objetivo pertenecía casi en su totalidad a esta Comunidad.

\section{Gráfico 2}

\section{Representación gráfica sobre el conocimiento del encuestado de la web} de Galicia

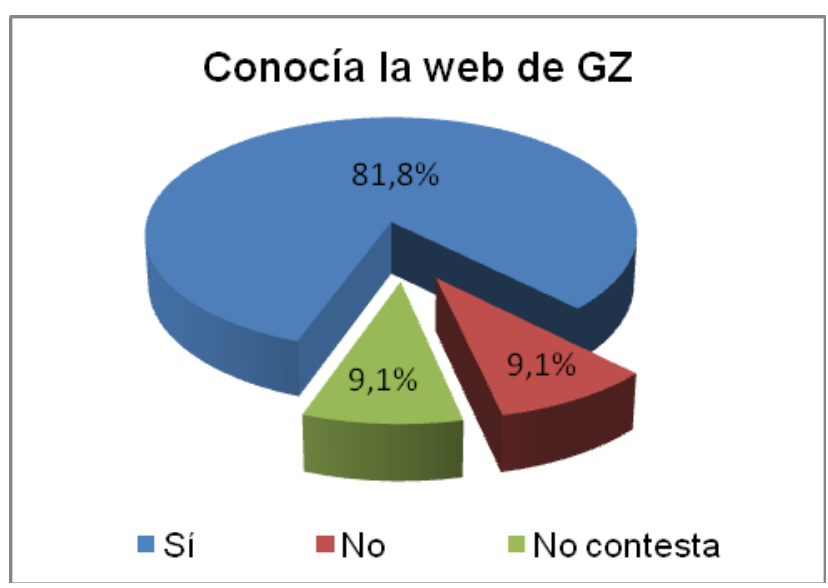

Fuente: Elaboración propia.

Mientras que como apuntan los datos expuestos, el resto de las páginas webs analizadas no resultaban tan conocidas por los usuarios, aunque existen diferencias entre el conocimiento de cada una de ellas que tenían previamente a esta encuesta los usuarios, (véase cuadro 3).

En el caso de la web asturiana, los resultados evidencian que parte de los encuestados habían accedido a esta web previamente, un 47\%, y los que no la conocían sumaban un porcentaje total de 43\%. Esta web no resultaba ser tan familiar como la de Galicia, pero aún así no resultaba extraña para un poco más de la mitad de los usuarios. 


\section{Cuadro 5}

\section{Distribución porcentual de conocimiento previo de las webs}

\begin{tabular}{|l|c|c|c|c|c|}
\hline \multicolumn{6}{|l|}{ Conocía las webs } \\
\hline & GZ & AS & C & EZ & CV \\
\hline Sí & 81,8 & 47,7 & 43,2 & 40,9 & 27,3 \\
\hline No & 9,1 & 43,2 & 47,7 & 50 & 63,6 \\
\hline $\begin{array}{l}\text { No } \\
\text { contesta }\end{array}$ & 9,1 & 9,1 & 9,1 & 9,1 & 9,1 \\
\hline
\end{tabular}

Fuente: Elaboración propia

Además, los datos indicados denotan que la web de Cantabria es menos conocida por los usuarios que las dos anteriores, es decir, Galicia y Asturias. Los que habían navegado con anterioridad a la realización de la encuesta en la web de Cantabria eran un 43,2\% de los encuestados y los que no la conocían en absoluto suman un $47,7 \%$. En este caso los que no la conocían, superan ligeramente a los que ya les era familiar.

Como podemos observar, en el caso de la web de Euskadi, el nivel de desconocimiento de la web aumenta con respecto a todas las webs anteriores, Galicia, Asturias y Cantabria. El porcentaje de aquellas personas que desconocían la web aumenta hasta un 50\%, mientras que disminuyen aquellos que habían navegado en esta web anteriormente (sólo un 40,9\%).

Finalmente, los resultados obtenidos sobre la web de la Comunidad Valenciana son los que distan más de los anteriores. En efecto, la web de la Comunidad Valenciana es la más extraña o desconocida para los usuarios de todas, sólo un 27,3\% había navegado anteriormente por el sitio. Mientras que un 63,6\% de los encuestados la desconocían. En este caso, los resultados casi se invierten con respecto a la web gallega.

Para concluir, es prudente tener en cuenta las siguientes observaciones:

Parece que la proximidad de los potenciales usuarios influye en el mayor o menos conocimiento de las webs de los destinos, pues se evidencia que 
aquellos destinos de más proximidad con respecto a los encuestadosrecordamos mayoritariamente gallegos- el conocimiento de sus webs es mayor, es decir; en primer lugar Galicia, su propia comunidad, seguido de Asturias, Cantabria y Euskadi, son según la distancia proporcionalmente más o menos visitadas sus webs. Esto tiene su lógica cuando sabemos que los destinos de proximidad son los más visitados en los desplazamientos de los españoles.

En los extremos, Galicia y la Comunidad Valenciana, la primera la web más visitada de antemano y la Comunidad Valenciana la más desconocida.

A continuación se presenta el análisis detallado de las medias y también un análisis de los grados de importancia de las variables. Se trata de un análisis pormenorizado de las puntuaciones obtenidas para cada ítem analizado, además del grado de dispersión para cada variable. Esta tabla contiene también la columna de la derecha con la media de valores según grado de importancia otorgada a cada variable o cada característica analizada y su grado de dispersión.

\section{Cuadro 6}

Análisis de medias de cada variable analizada y su grado de importancia.

\begin{tabular}{|c|c|c|c|c|c|c|c|c|c|c|c|c|}
\hline & \multicolumn{2}{|c|}{ GZ } & \multicolumn{2}{|c|}{ AS } & \multicolumn{2}{|r|}{ C } & \multicolumn{2}{|c|}{ EZ } & \multicolumn{2}{|c|}{ cV } & \multicolumn{2}{|c|}{$\begin{array}{l}\text { IMPORTAN } \\
\text { CIA }\end{array}$} \\
\hline & $\begin{array}{l}\mathrm{ME} \\
\mathrm{DIA}\end{array}$ & $\begin{array}{l}\text { DESV } \\
\text { TIP. }\end{array}$ & $\begin{array}{l}\text { ME } \\
\text { DIA }\end{array}$ & $\begin{array}{l}\text { DESV } \\
\text {. TIP. }\end{array}$ & $\begin{array}{l}\text { ME } \\
\text { DIA }\end{array}$ & $\begin{array}{l}\text { DESV } \\
\text {. TIP. }\end{array}$ & $\begin{array}{l}\text { ME } \\
\text { DIA }\end{array}$ & $\begin{array}{l}\text { DESV } \\
\text { TIP. }\end{array}$ & $\begin{array}{l}\text { ME } \\
\text { DIA }\end{array}$ & $\begin{array}{l}\text { DESV } \\
\text { TIP. }\end{array}$ & $\begin{array}{l}\text { ME } \\
\text { DIA }\end{array}$ & $\begin{array}{l}\text { DESV } \\
\text { TIP. }\end{array}$ \\
\hline Valora la velocidad de carga de la web & $\begin{array}{c}4,0 \\
7\end{array}$ & 0,873 & $\begin{array}{c}2,9 \\
5\end{array}$ & 1,275 & $\begin{array}{c}3,5 \\
2\end{array}$ & 1,089 & $\begin{array}{c}3,5 \\
2\end{array}$ & 1,067 & $\begin{array}{c}4,1 \\
6\end{array}$ & 0,834 & $\begin{array}{c}4,2 \\
3\end{array}$ & 0,649 \\
\hline $\begin{array}{l}\text { ¿Es coherente la imagen de la página con la imagen que tu tienes del } \\
\text { destino? }\end{array}$ & $\begin{array}{c}3,4 \\
1\end{array}$ & 1,041 & $\begin{array}{c}4,1 \\
1\end{array}$ & 0,868 & $\begin{array}{c}3,6 \\
1\end{array}$ & 0,895 & $\begin{array}{c}3,4 \\
1\end{array}$ & 0,972 & $\begin{array}{c}3,6 \\
8\end{array}$ & 1,006 & $\begin{array}{c}3,5 \\
5\end{array}$ & 0,968 \\
\hline $\begin{array}{l}\text { ¿Crees que un sordo o un invidente pueden informarse de una manera } \\
\text { precisa tras visitar la web? }\end{array}$ & $\begin{array}{c}1,7 \\
4\end{array}$ & 0,966 & $\begin{array}{c}1,8 \\
5\end{array}$ & 1,04 & $\begin{array}{c}1,7 \\
7\end{array}$ & 0,842 & $\begin{array}{c}1,9 \\
2\end{array}$ & 0,957 & $\begin{array}{c}2,0 \\
5\end{array}$ & 1,099 & $\begin{array}{c}3,8 \\
2\end{array}$ & 0,801 \\
\hline Tiene un diseño atractivo & 2,9 & 1,172 & $\begin{array}{c}3,2 \\
8\end{array}$ & 0,847 & $\begin{array}{c}2,6 \\
3\end{array}$ & 0,868 & $\begin{array}{c}3,2 \\
3\end{array}$ & 0,862 & $\begin{array}{c}3,2 \\
3\end{array}$ & 1,143 & $\begin{array}{c}3,8 \\
4\end{array}$ & 0,886 \\
\hline ¿Indica claramente el tratamiento de tus datos personales y su utilización? & 2 & 1,257 & $\begin{array}{c}2,2 \\
9\end{array}$ & 1,346 & $\begin{array}{c}1,8 \\
3\end{array}$ & 1,107 & $\begin{array}{c}2,3 \\
3\end{array}$ & 1,347 & 2,6 & 1,392 & $\begin{array}{c}3,6 \\
9\end{array}$ & 1,104 \\
\hline $\begin{array}{l}\text { ¿Crees que esta página indica adecuadamente que es la oficial del destino } \\
\text { turístico? }\end{array}$ & $\begin{array}{c}3,2 \\
1\end{array}$ & 1,317 & $\begin{array}{c}3,4 \\
8\end{array}$ & 1,131 & $\begin{array}{c}3,4 \\
5\end{array}$ & 1,173 & $\begin{array}{c}3,1 \\
2\end{array}$ & 1,269 & 4 & 1,148 & 3,5 & 0,994 \\
\hline ¿Posee una lista de enlaces útiles a otras páginas relacionadas? & $\begin{array}{c}3,2 \\
5\end{array}$ & 1,081 & $\begin{array}{c}3,6 \\
6\end{array}$ & 0,987 & $\begin{array}{c}3,3 \\
2\end{array}$ & 1,052 & $\begin{array}{c}3,0 \\
9\end{array}$ & 0,884 & $\begin{array}{c}3,4 \\
8\end{array}$ & 1,151 & $\begin{array}{c}3,4 \\
9\end{array}$ & 0,81 \\
\hline Innovadora & $\begin{array}{c}2,5 \\
8\end{array}$ & 1,035 & 2,8 & 0,939 & $\begin{array}{c}2,6 \\
8\end{array}$ & 0,764 & $\begin{array}{c}3,0 \\
3\end{array}$ & 0,832 & $\begin{array}{c}3,2 \\
5\end{array}$ & 1,149 & $\begin{array}{c}3,3 \\
2\end{array}$ & 0,842 \\
\hline ¿Se navega intuitivamente y se orienta uno fácilmente la web? & $\begin{array}{c}3,4 \\
5\end{array}$ & 1,044 & $\begin{array}{c}3,6 \\
8\end{array}$ & 0,857 & $\begin{array}{c}3,3 \\
2\end{array}$ & 0,983 & $\begin{array}{c}3,6 \\
1\end{array}$ & 0,97 & $\begin{array}{c}3,7 \\
5\end{array}$ & 0,967 & $\begin{array}{c}4,2 \\
6\end{array}$ & 0,665 \\
\hline
\end{tabular}




\begin{tabular}{|c|c|c|c|c|c|c|c|c|c|c|c|c|}
\hline ¿El contacto con el organismo gestor del destino en la página es sencillo? & $\begin{array}{c}3,3 \\
2\end{array}$ & 1,254 & $\begin{array}{c}3,2 \\
1\end{array}$ & 1,159 & 3,4 & 1,061 & $\begin{array}{c}3,2 \\
6\end{array}$ & 1,149 & $\begin{array}{c}3,7 \\
9\end{array}$ & 0,951 & 3,5 & 0,944 \\
\hline ¿Existe un buscador rápido y potente de contenidos en la propia página? & $\begin{array}{c}3,6 \\
1\end{array}$ & 0,919 & $\begin{array}{c}3,3 \\
8\end{array}$ & 1,168 & $\begin{array}{c}3,6 \\
4\end{array}$ & 1,078 & $\begin{array}{c}3,5 \\
5\end{array}$ & 0,993 & $\begin{array}{c}3,5 \\
2\end{array}$ & 1,042 & $\begin{array}{c}3,7 \\
6\end{array}$ & 0,932 \\
\hline ¿Los idiomas en que se puede leer son adecuados? & $\begin{array}{c}4,4 \\
1\end{array}$ & 0,816 & $\begin{array}{c}3,3 \\
9\end{array}$ & 1,146 & $\begin{array}{c}3,7 \\
5\end{array}$ & 1,014 & 3,8 & 0,93 & $\begin{array}{c}4,3 \\
5\end{array}$ & 0,752 & 4 & 0,988 \\
\hline $\begin{array}{l}\text { ¿Cómo valoras la calidad en recursos multimedia (fotografías, vídeos, audio, } \\
\text { visitas virtuales, webcam? }\end{array}$ & $\begin{array}{c}3,0 \\
5\end{array}$ & 0,987 & $\begin{array}{c}2,9 \\
5\end{array}$ & 0,914 & $\begin{array}{c}3,0 \\
5\end{array}$ & 0,806 & $\begin{array}{c}3,0 \\
9\end{array}$ & 0,709 & $\begin{array}{c}3,5 \\
2\end{array}$ & 1,067 & 3,9 & 0,759 \\
\hline Ofrece mayor variedad de productos y servicios & $\begin{array}{c}3,1 \\
8\end{array}$ & 0,823 & $\begin{array}{c}3,4 \\
1\end{array}$ & 0,715 & $\begin{array}{c}3,5 \\
6\end{array}$ & 0,852 & $\begin{array}{c}3,4 \\
9\end{array}$ & 0,644 & $\begin{array}{c}3,8 \\
2\end{array}$ & 0,79 & 3,7 & 0,909 \\
\hline ¿La imagen de la página da valor al destino y lo hace más atractivo? & $\begin{array}{c}3,0 \\
2\end{array}$ & 1,285 & $\begin{array}{c}3,5 \\
2\end{array}$ & 1,067 & $\begin{array}{c}3,1 \\
8\end{array}$ & 0,815 & $\begin{array}{c}3,4 \\
3\end{array}$ & 0,846 & $\begin{array}{c}3,3 \\
2\end{array}$ & 1,157 & $\begin{array}{c}3,9 \\
8\end{array}$ & 0,749 \\
\hline $\begin{array}{l}\text { ¿Presenta el sitio información clara sobre los distintos tipos de actividades y } \\
\text { sus ubicaciones? }\end{array}$ & $\begin{array}{c}3,4 \\
1\end{array}$ & 1,019 & $\begin{array}{c}3,5 \\
2\end{array}$ & 0,952 & $\begin{array}{c}3,5 \\
5\end{array}$ & 0,82 & $\begin{array}{c}3,6 \\
4\end{array}$ & 0,78 & $\begin{array}{c}3,6 \\
1\end{array}$ & 0,868 & $\begin{array}{c}4,0 \\
7\end{array}$ & 0,745 \\
\hline ¿Encuentras fácilmente lo que buscas / facilidad de uso? & $\begin{array}{c}3,5 \\
2\end{array}$ & 1,045 & $\begin{array}{c}3,3 \\
9\end{array}$ & 0,813 & $\begin{array}{c}3,4 \\
5\end{array}$ & 0,761 & $\begin{array}{c}3,3 \\
6\end{array}$ & 0,613 & $\begin{array}{c}3,6 \\
1\end{array}$ & 0,813 & $\begin{array}{c}4,3 \\
6\end{array}$ & 0,618 \\
\hline ¿La información es actualizada y fidedigna? & $\begin{array}{c}3,4 \\
4\end{array}$ & 0,968 & $\begin{array}{c}3,5 \\
4\end{array}$ & 0,869 & $\begin{array}{c}3,6 \\
1\end{array}$ & 0,803 & $\begin{array}{c}3,8 \\
6\end{array}$ & 0,762 & $\begin{array}{c}3,8 \\
4\end{array}$ & 0,886 & $\begin{array}{c}4,6 \\
5\end{array}$ & 0,533 \\
\hline ¿Dispone de variedad de ofertas especiales y de última hora? & $\begin{array}{c}2,7 \\
8\end{array}$ & 1,129 & $\begin{array}{c}2,5 \\
6\end{array}$ & 1,226 & $\begin{array}{c}2,6 \\
7\end{array}$ & 1,221 & $\begin{array}{c}2,5 \\
4\end{array}$ & 1,098 & $\begin{array}{c}2,7 \\
6\end{array}$ & 1,067 & $\begin{array}{c}3,7 \\
4\end{array}$ & 0,885 \\
\hline $\begin{array}{l}\text { ¿A través de la web podemos fácilmente comunicarnos con otros usuarios } \\
\text { mediante chats, foros...correos...? }\end{array}$ & $\begin{array}{c}1,7 \\
4\end{array}$ & 0,95 & $\begin{array}{c}1,8 \\
5\end{array}$ & 0,933 & $\begin{array}{c}1,6 \\
9\end{array}$ & 0,731 & $\begin{array}{c}2,0 \\
8\end{array}$ & 1,201 & $\begin{array}{c}2,1 \\
5\end{array}$ & 1,159 & $\begin{array}{c}2,8 \\
5\end{array}$ & 1,204 \\
\hline ¿Contratar y comprar servicios turísticos on-line es sencillo y práctico? & 2,9 & 1,215 & $\begin{array}{c}2,4 \\
4\end{array}$ & 1,188 & $\begin{array}{c}2,7 \\
2\end{array}$ & 1,213 & $\begin{array}{c}2,6 \\
1\end{array}$ & 1,104 & $\begin{array}{c}3,0 \\
3\end{array}$ & 1,219 & $\begin{array}{c}3,8 \\
1\end{array}$ & 0,862 \\
\hline
\end{tabular}

Fuente: Elaboración propia

Los datos de la columna de la derecha expresan el grado de importancia de cada característica analizada, podemos concluir que son seis las variables más apreciadas por el usuario, es decir, aquellas que obtienen un valor 4 o superior.

La característica más importante desde el punto de vista del usuario es que la información sea actualizada y fidedigna. En orden de importancia los usuarios exigen en segundo lugar la facilidad de uso en una web de destino turístico. En tercer lugar es muy significativa para el usuario la navegación intuitiva, es decir, la orientación fácil en la web. La cuarta característica en orden de importancia es la velocidad de carga de la web y finalmente en quinto lugar figura la presentación clara sobre los distintos tipos de actividades y sus ubicaciones. Aunque con puntuaciones muy próximas a 4 en grado de importancia destacan a continuación en sexto lugar la imagen de la página que da valor al destino y lo hace más atractivo y por último la calidad de los recursos multimedia. 
En el siguiente gráfico se han cotejado las medias obtenidas en relación al peso de la importancia otorgada a cada variable por parte del encuestado.

\section{Gráfico 3}

Dispersión de la media de cada web con respecto a la media de la importancia en cada uno de los ítems

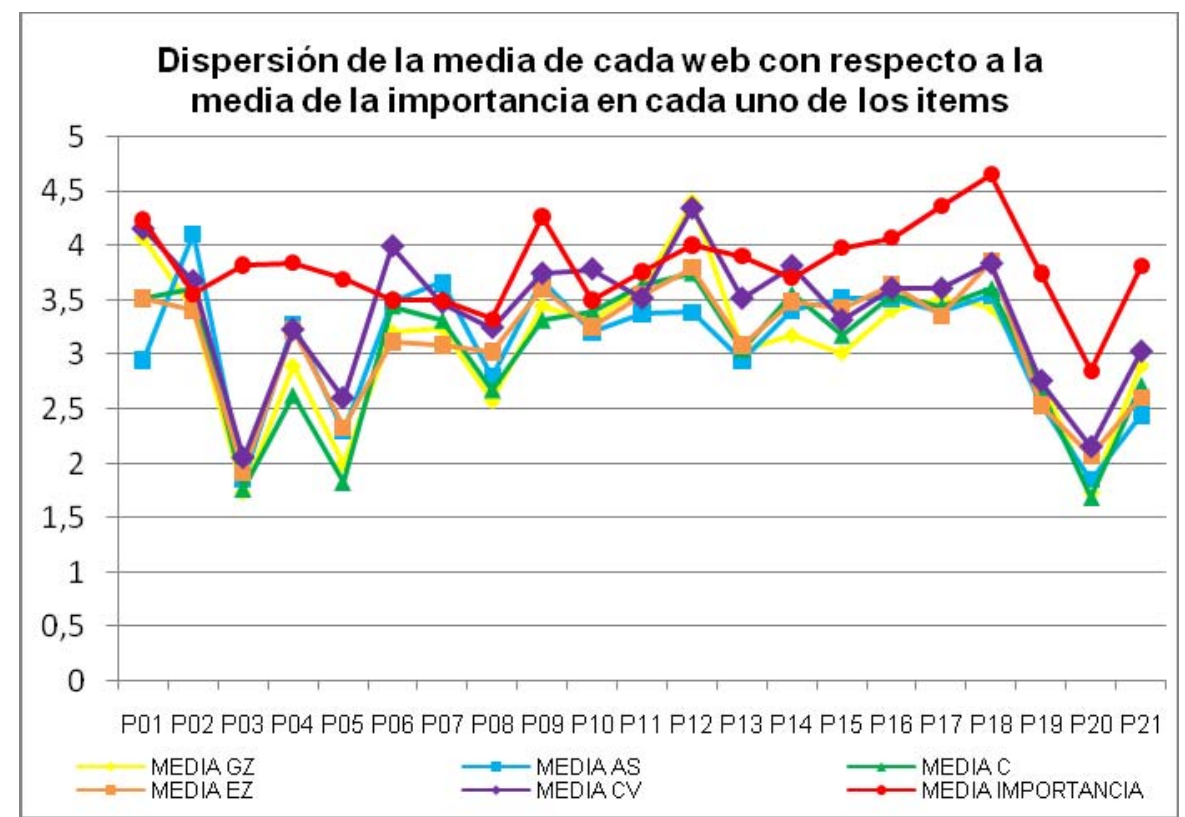

Fuente: Elaboración propia.

Los picos que indican mayor dispersión con respecto a la media de importancia otorgada muestran que los usuarios han valorado muy por debajo del grado de importancia para ellos; la capacidad de ofrecer en las páginas en general accesibilidad para los discapacitados e indicación clara de sus datos personales. Igualmente ocurre para la característica más importante que debe poseer una web según los encuestados, la información actualizada y fidedigna.

El siguiente gráfico indica una impresión global de las bondades o factores de mayor éxito de cada webs, así como también se perciben sus deficiencias en grado comparativo. 


\section{Gráfico 4}

\section{Gráfico de perfiles con respecto a la media de Galicia, Asturias y CV}

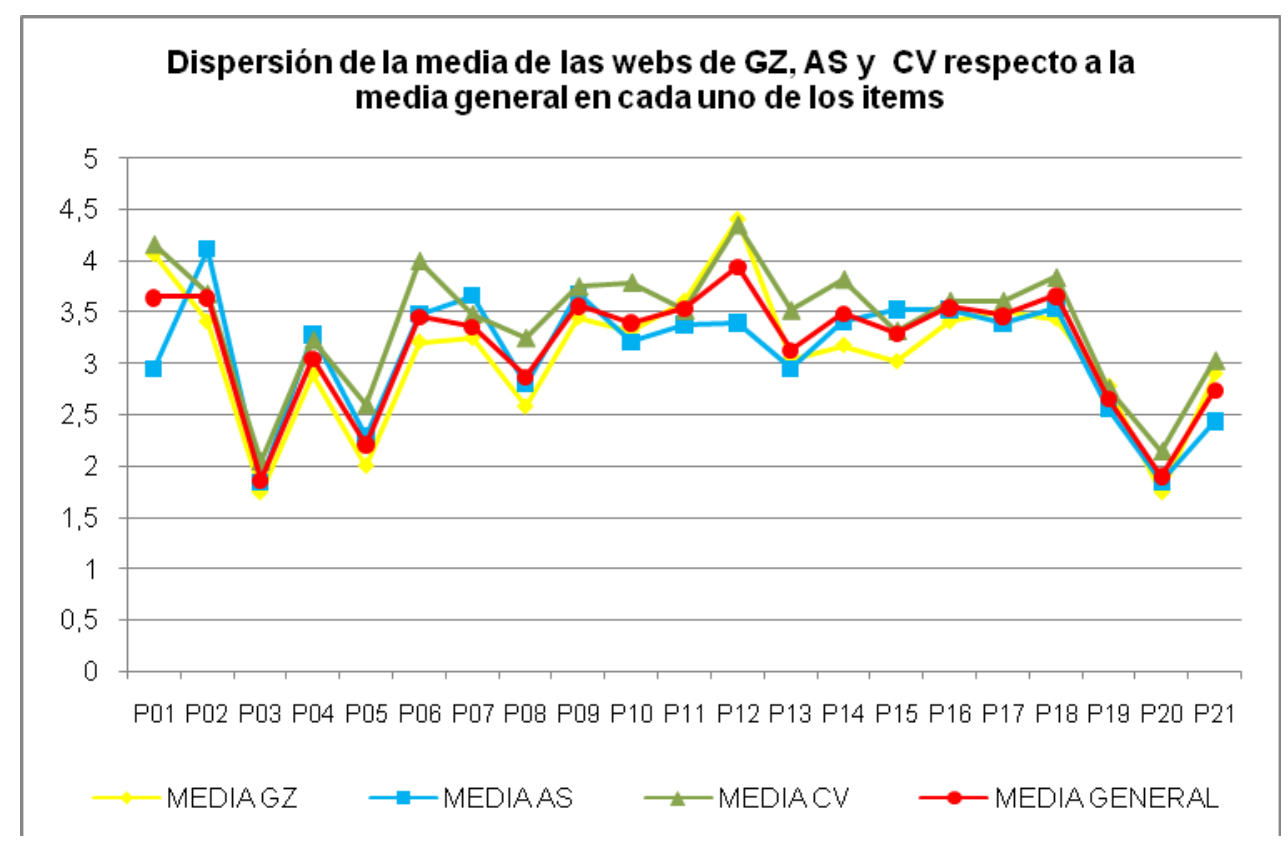

Fuente: Elaboración propia.

Cómo se presenta en el gráfico, la web Valenciana apenas posee ninguna característica valorada a un nivel inferior a la media general, mientras las otras dos webs, Galicia y Asturias exhiben unos valores muy similares a la media general de todas las webs analizadas.

\section{Cuadro 7}

Preguntas formuladas en la encuesta.

P01Valora la velocidad de carga de la web

P02¿Es coherente la imagen de la página con la imagen que tú tienes del destino?

P03 ¿Crees que un sordo o un invidente pueden informarse de una manera precisa tras visitar la web?

P04Tiene un diseño atractivo

P05¿Indica claramente el tratamiento de tus datos personales y su utilización?

P06¿Crees que esta página indica adecuadamente que es la oficial del destino 


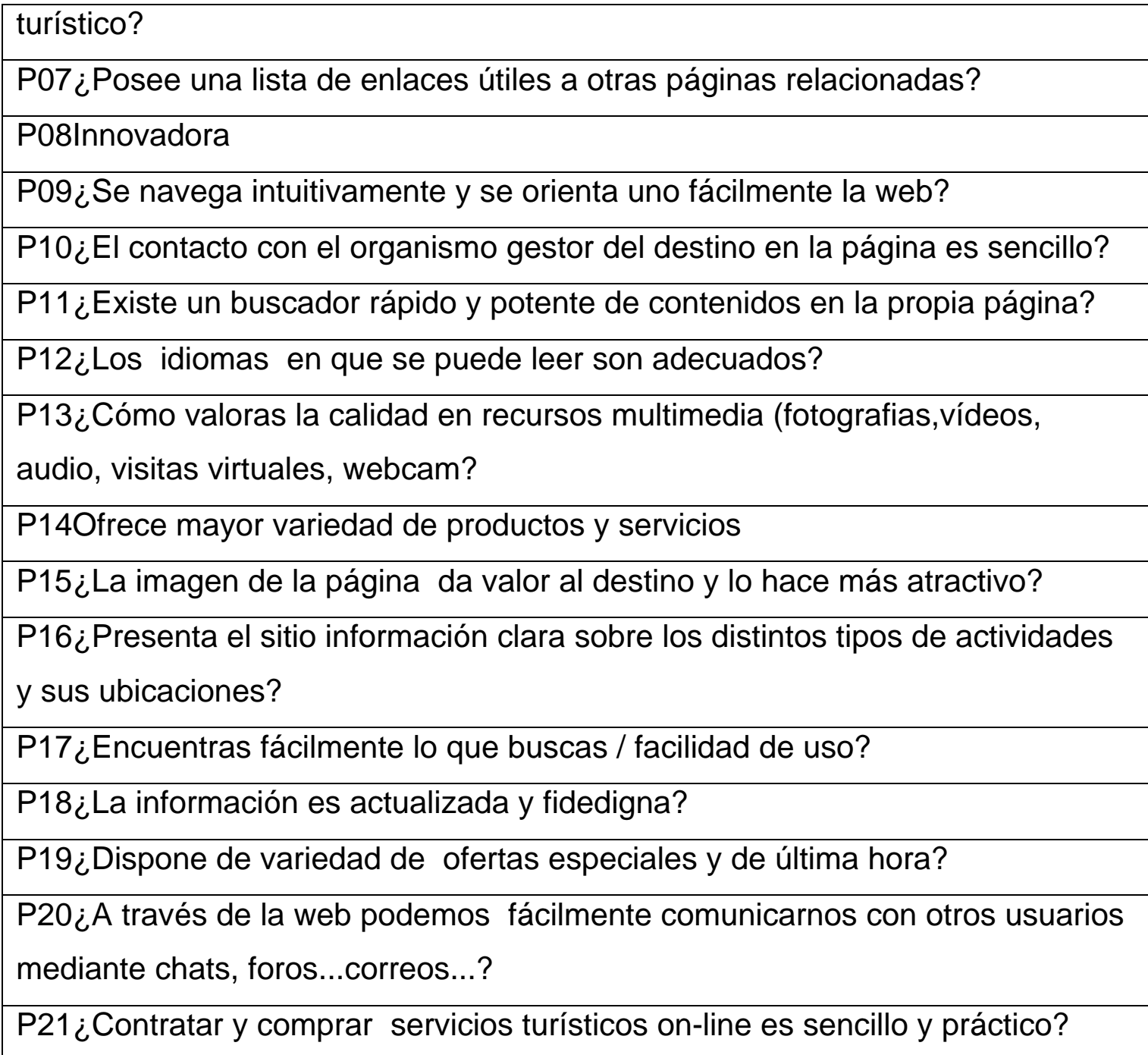

\subsubsection{Análisis importancia-valoración.}

Los siguientes gráficos de dispersión muestran el resultado del análisis realizado de manera independiente para cada una de las webs oficiales de las Comunidades Autónomas. Se pretende aportar una visión gráfica para cada una de las webs que nos desvela/revela información relativa a las variables en las que inexorablemente se debe actuar. Nos ha permitido cotejar la valoración otorgada versus la importancia de cada ítem según los usuarios.

La cuadrícula forma varios cuadrantes generales (A-D) que se describen a continuación:

Cuadrante A (superior izquierda). Es necesario hacer modificaciones. 
Cuadrante B (superior derecha). Buen trabajo. No hay necesidad de modificar. Cuadrante C (inferior izquierda). No hay que preocuparse: baja prioridad.

Cuadrante D (inferior derecha). Hay que pensar de nuevo en el asunto. Posible rehechura de todo.

\section{Gráfico 5}

\section{Representación para la web gallega y variables analizadas}

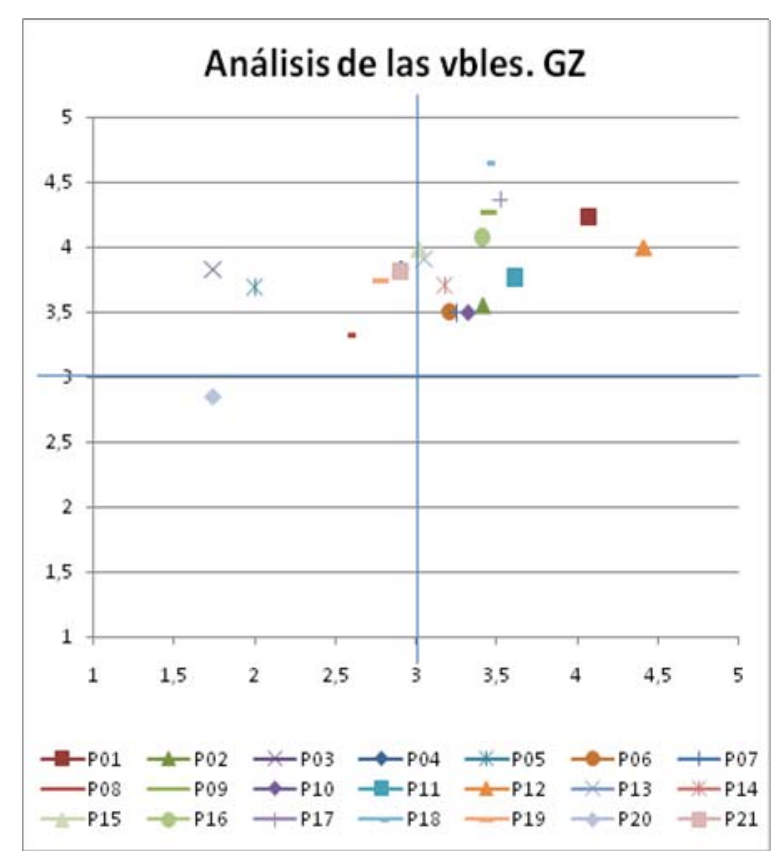

Fuente: Elaboración propia.

En relación a la web de Galicia, se observan en el cuadrante B (cuadrante derecha superior), las variables que no habría necesidad de modificar.

Por el contrario los factores críticos subrayados por los encuestados en los que habría que intervenir son su falta de accesibilidad para discapacitados, al igual que podemos observar en otras las webs, la falta de especificación clara de los datos personales del usuario y su utilización, la innovación en la página, escasa variedad de ofertas especiales y de última hora, y mejorar la contratación y compra de servicios turísticos on-line. La posibilidad de comunicarse con otros usuarios, en el cuadrante $C$ parece ser menos relevante para los usuarios. 


\section{Gráfico 6}

\section{Análisis de las variables de la web de Asturias}

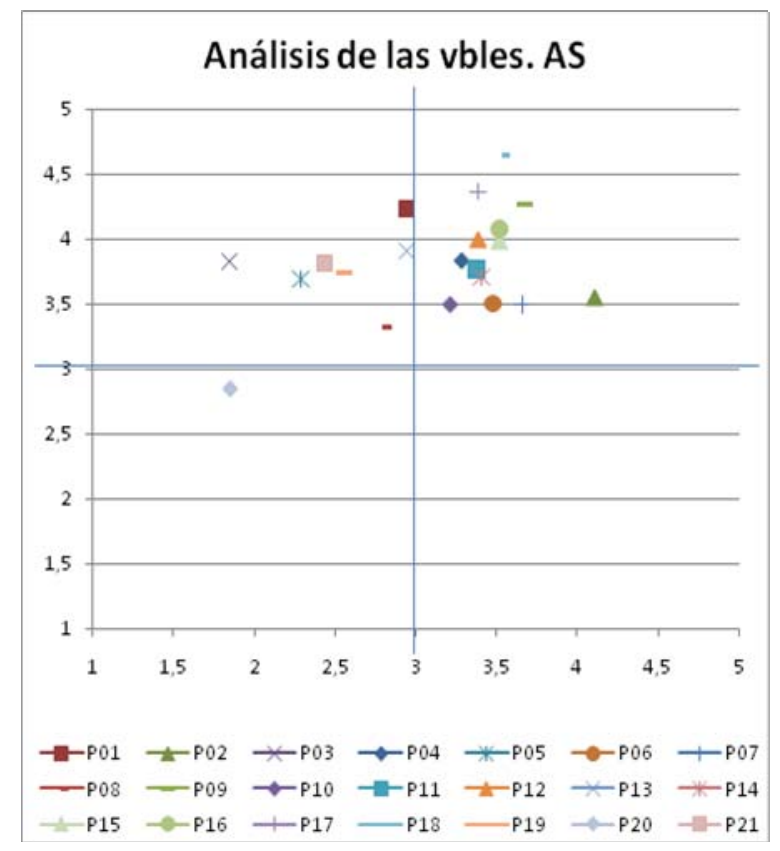

Fuente: Elaboración propia

En la web de Asturias destacan otros factores, el más valorado como se presenta en el cuadrante B (derecha superior) corresponde a la coherencia de la imagen de la página con la imagen que tienen los usuarios del destino. Su navegación intuitiva y fácil orientación en la web es otro punto favorable al igual que su lista de enlaces a páginas relacionadas. Las deficiencias (cuadrante A, superior izquierda) que se señalan son las mismas que en el caso de la web gallega, además de señalar la baja velocidad de carga de la web y la calidad de recursos multimedia como aspectos a modificar.

\section{Gráfico 7}

Análisis de las variables de la web de la Comunidad Valenciana. 


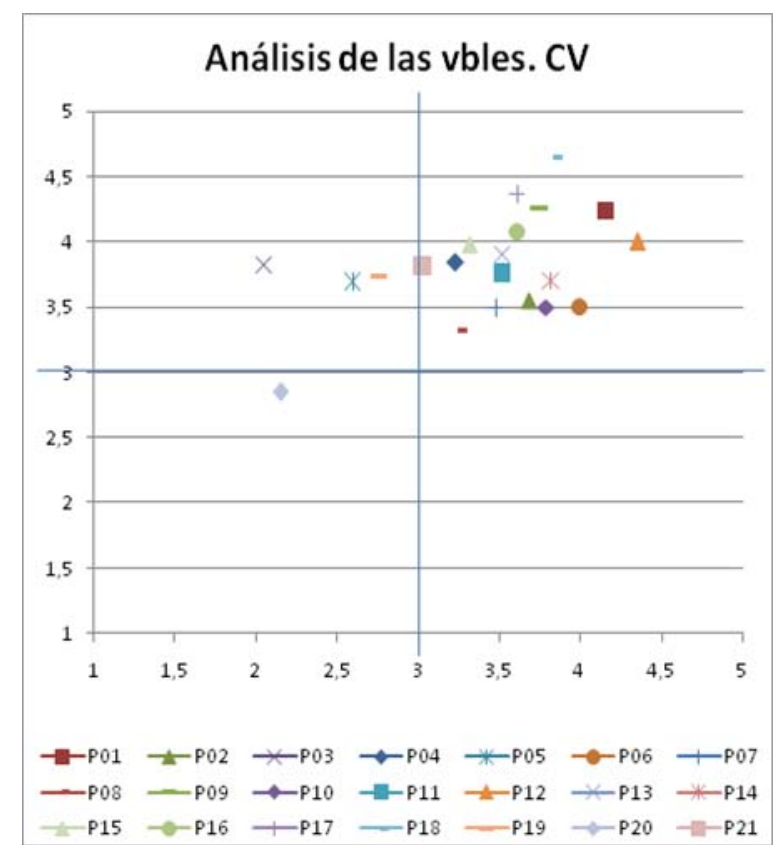

Fuente: Elaboración propia

Múltiples son los aspectos muy valorados en la web de la Comunidad Valenciana, en primer lugar sus idiomas, también la velocidad de carga y la claridad con la que expresa su oficialidad, entre otras características (véase cuadrante B, superior derecha). En cuanto a las características mejorables (cuadrante A izquierda superior), en esta página sólo se acentúan tres: la baja adecuación a discapacitados de la web, aspecto que se enfatiza en líneas generales para todas las webs, la claridad con la que se indica el tratamiento de los datos personales de los usuarios y la variedad de ofertas especiales y de última hora. Las bajas posibilidades de comunicación de los usuarios vía chats, foros, correos, factor a mejorar también de manera global, pero de baja importancia para el usuario (cuadrante C, izquierda inferior).

En el siguiente gráfico circular se muestran los resultados globales y la estimación que los usuarios manifiestan con respecto a la bondad de cada web. 
La mejor calidad de los atributos que se evaluaban para las webs, es decir, en general la web mejor puntuada con respecto a las variables analizadas por los encuestados ha sido en primer lugar, para la Comunidad Valenciana que reúne un total de 7,07 puntos, a continuación le sigue la web de Galicia que obtiene una valoración media global de 6,5 puntos muy similar a la web de la Comunidad Asturiana que ocupa el tercer lugar del ranking con un total de 6,43 puntos. El cuarto lugar lo ocupa la web de Euskadi valorada con 6,39 puntos y por en el último puesto del ranking se encuentra la web de Cantabria con 6,27 puntos.

\section{Gráfico 8}

\section{Representación de las valoraciones globales de todas las webs}

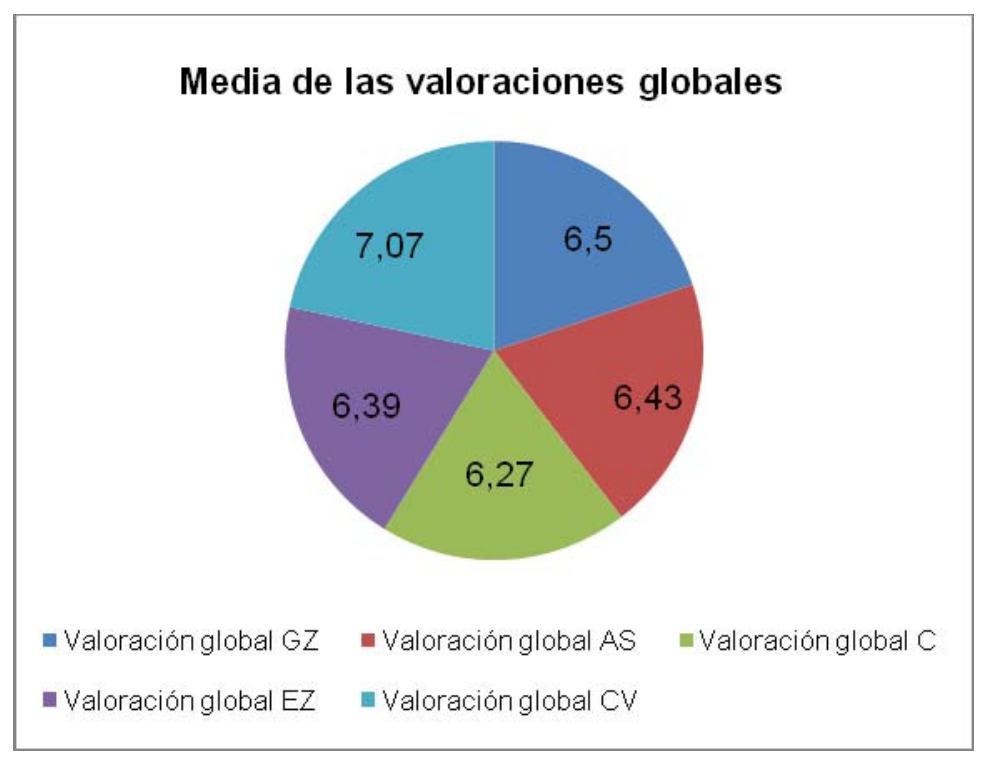

Fuente: Elaboración propia.

El indicador que se muestra a continuación, es un número índice de preferencia. Se ha multiplicado la puntuación por la importancia y se ha promediado.

El número índice nos permite en términos relativos comparar unas webs con otras, corrige un poco la media. 
INDICADORES DE PREFERENCIA

$$
I P=\frac{\sum_{i=1}^{n} \sum_{i=1}^{n}\left(X_{i} * I_{i}\right)}{n}
$$

- $\quad$ Indicador de preferencia de $\mathrm{GZ}\left(\mathrm{IP}_{\mathrm{GZ}}\right)=231,50$

- Indicador de preferencia de $\mathrm{AS}\left(\mathrm{IP}_{\mathrm{GZ}}\right)=231,23$

- $\quad$ Indicador de preferencia de $\mathrm{C}\left(\mathrm{IP}_{\mathrm{GZ}}\right)=226,75$

- $\quad$ Indicador de preferencia de $E Z\left(\mathrm{IP}_{\mathrm{GZ}}\right)=232,43$

- Indicador de preferencia de CV $\left(\mathrm{IP}_{\mathrm{CV}}\right)=254,00$

\section{Cuadro 6}

Indicadores de preferencia

Media General

$235,182(=100 \%)$

\begin{tabular}{|c|c|c|}
\hline COMUNIDAD & IP & Valor \% indiciado \\
\hline GZ & 231,50 & $98,86 \%$ \\
\hline AS & 231,23 & $98,74 \%$ \\
\hline C & 226,75 & $96,84 \%$ \\
\hline EZ & 232,43 & $99,26 \%$ \\
\hline CV & 254,00 & $108,43 \%$ \\
\hline
\end{tabular}

Fuente: Elaboración propia

La web de Galicia tiene un peso y valoración equivalente a las otras webs de España Verde, pero la Comunidad Valenciana es la más potente, lo cual quiere decir que el resto debe mejorar e incorporar elementos que valoran los consumidores.

A partir de los datos expuestos y la consulta a expertos podemos establecer las siguientes conclusiones, que sin tener un carácter definitivo nos apuntan algunos aspectos muy sugerentes y de inmediata aplicación. 


\section{Conclusiones}

Cómo se ha constatado, las posibilidades para la promoción de los destinos turísticos que tiene Internet y la world wide web para la promoción de los destinos turísticos pueden ser estudiadas a través del sitio web oficial del destino.

Esta metodología supone un análisis sistemático de un gran número de variables de cada sitio web y esto le otorga unas características únicas en las investigaciones realizadas hasta el momento, creemos que bastante útil para los gestores de los destinos turísticos.

Quizá la aportación más interesante de este estudio es la aplicación de técnicas de análisis factorial. Este análisis nos permite condensar o resumir la información contenida en nuestro grupo de ítems o variables a un número menor, que nos permitirá crear nuevas variables que serán denominadas factores o componentes.

Los resultados de este estudio arrojan conclusiones en muchos sentidos:

En líneas generales se puede concluir que los factores críticos o déficits más acusados han sido las características P03 Y P20, es decir, el nivel de accesibilidad para discapacitados de las webs y la posibilidad de comunicarse con otros usuarios mediante chats, foros, correos.., que desde nuestro punto de vista limita la interactividad, pero además reduce también el nivel de información de la web.

Estos ítems han sido valorados por debajo de un nivel deficiente, es decir, los usuarios han manifestado que no se cumplen en absoluto, en una media general, para todas las páginas, Además, inferior a un nivel aceptable, por debajo de 3 puntos, son catalogados los siguientes ítems: P05, P08 Y P19, esto significa que los usuarios en general no encuentran aceptable o clara en la mayoría de las webs la indicación de tratamiento de sus datos personales y su 
utilización, la innovación en general y finalmente la capacidad de ofrecer ofertas especiales y de última hora. Dicho de otra manera, no se ofrece un nivel aceptable de identidad y confianza para efectuar transacciones en línea, las páginas deberían ser más innovadoras y por último el nivel de la información es deficiente en cuanto a ofertas especiales y de última hora.

Por el contrario, los puntos fuertes que los usuarios han valorado muy positivamente y han apreciado en líneas generales, en primer lugar, un aspecto relacionado con las características técnicas, este es la velocidad de carga de las webs (P01), salvo claras excepciones.

Además, es ensalzado un aspecto de Imagen, pues estiman más que aceptable la coherencia de la imagen de las páginas con la imagen que tienen del destino (P02).

Valoran también la navegación, ya que consideran aceptable en general la navegación intuitiva y la orientación en las webs (P09), los buscadores (P11) y destaca como variable más valorada en general, los idiomas de los que dispone cada web.

Otras características bastante aceptables son: la información que ofrecen (P16) sobre actividades y ubicaciones y (P18), la actualización y veracidad de las mismas.

De estas características analizadas, se han determinado las que suponen un nivel de importancia vital en una web de un destino turístico, según la valoración del usuario.

Pero, la aportación más significativa es sin duda, la reducción de los factores.

Por último, es muy significativo que ninguna web analizada de la España Verde no haya obtenido mayor valor que la web de la Comunidad Valenciana. 


\section{Bibliografía}

ALONSO, A., FIGUEROA, C., RODRÍGUEZ, J., TALÓN, P. (2008): "El impacto de la tecnología social en las decisiones de consumo turístico". En TURITEC 2008, VII Congreso de Turismo y Tecnologías de la Información y de las Comunicaciones, Málaga 25 Y 26 de septiembre de 2008.

CELAYA, J. (2009): "Visibilidad de las ciudades en la web 2.0". En VI Jornadas de Marketing de Ciudades. "Arte y patrimonio en la percepción y el rediseño de la ciudad. A Coruña, 24 de abril de 2009.

CELAYA, J. (2008) "La empresa en la web 2.0". El impacto de las redes sociales y las nuevas formas de comunicación online en la estrategia empresarial. Gestión 2000.

DA CRUZ, G. y DE CAMARGO, P (2008): "Estrategias de promoción en la web: análisis de destinos turísticos internacionales". Estudios y perspectivas en turismo, vol. 17, pp 156-169. Ciudad Autónoma de Buenos Aires. Centro de Investigaciones y Estudios Turísticos.

FERNÁNDEZ, J. y HUERTAS A. (2008) "Ciudades en la web: usabilidad e interactividad de las páginas oficiales de los destinos turísticos". En: V Jornadas de Marketing de ciudades, A Coruña 9, 10 y 11 de abril de 2008.

FERNÁNDEZ, J. y HUERTAS A. (2008) "El E-Marketing como nueva forma de comunicar la marca-ciudad". En: $V$ Jornadas de Marketing de Ciudades, A Coruña 9, 10 y 11 de abril de 2008.

HUERTAS, A. (2008): "Aplicación de la Web 2.0 a los destinos turísticos". En TURITEC 2008, VII Congreso de Turismo y Tecnologías de la Información y de las Comunicaciones, Málaga 25 Y 26 de septiembre de 2008.

ORGANIZACIÓN MUNDIAL DEL TURISMO (2005): Evaluación y optimización de sitios web. El servicio "Destination web watch". Consejo Empresarial de la OMT (CEOMT). Madrid. 
ORGANIZACIÓN MUNDIAL DEL TURISMO (2008) Handbook on E-marketing for Tourism Destinations. Consejo Empresarial de la OMT (CEOMT). Madrid.

TRASPALACIOS, G., VÁZQUEZ, R., BELLO, L. (2005): Investigación de mercados. Métodos de recogida y análisis de la información para la toma de decisiones en marketing. Thomson Ed. Paraninfo, S.A., Madrid.

YOUNG, A.; PARK AND ULRIKE GRETZEL (2007): "Success Factors for Destination Marketing Web Sites: A Qualitative Meta-Analysis", Journal of Travel Research, vol 46, pp. 46-63.

\section{Para citar este artículo:}

Bello Acebrón, Laurentino - Penelas, Montserrat - Bellas, Cortés (21-12-2009). .

REDMARKA - CIECID - Unidad de Investigación en Marketing Aplicado-Universidad de A Coruña, Número 3, V1, pp.41-78

ISSN 1852-2300

URL del Documento : http://www.cienciared.com.ar/ra/doc.php?n=1164 